\title{
Implicações nutricionais e sensoriais da polpa e casca de baru (Dipterix Alata vog.) na elaboração de pães
}

\author{
Use of peel and pulp of baru in the development of bread
}

Lorena Santana ROCHA ${ }^{2 *}$, Raquel de Andrade CARDOSO SANTIAGO ${ }^{1}$

\begin{abstract}
Resumo
O interesse por novas fontes de nutrientes e a necessidade de preservação das espécies nativas do cerrado por meio de sua valorização motiva maiores esforços em investigar seu potencial para a suplementação de produtos. O objetivo deste trabalho foi investigar a viabilidade do uso da casca e polpa do baru no desenvolvimento de pães do tipo fôrma e suas consequentes implicações nutricionais e sensoriais. A partir da formulação de um pão de fôrma integral padrão, substitui-se o farelo de trigo por casca e polpa de baru em quatro proporções (25, 50 , 75 e 100\%). A análise da composição química da casca e polpa do baru resultou em 21,05\% de umidade, 65,01\% de carboidratos, 3,30\% de lipídios, 4,45\% de proteínas, 1,79\% de cinzas e 4,39\% de fibra bruta. Todas as amostras foram aceitas quanto aos atributos aparência, textura e sabor, foram consideradas com baixo teor de gorduras totais $(2,18 \%)$, não apresentando diferença significativa entre si quanto ao teor de proteína (13,59\%) e de umidade (34,54\%), e com teor médio de 41,90\% de carboidratos e 1,76\% de cinzas. Observou-se um acréscimo de até $58,20 \%$ no teor de fibra alimentar total com o aumento da proporção da casca e polpa do baru. A pesquisa realizada permite deduzir que a casca e polpa do baru são ingredientes viáveis para aplicação tecnológica em pão de fôrma integral, conferindo melhoria nas características nutricionais e atributos sensoriais.
\end{abstract}

Palavras-chave: panificação; nutrição; análise sensorial; composição química.

\begin{abstract}
Interest in new sources of nutrients and the need of preserving native species of the savanna, through their valorization, motivates the study of their potential for supplementing products. The objective of this study was to investigate the feasibility of using the peel and pulp of the baru to develop sliced bread and the consequent nutritional and sensory implications. In the process of developing whole wheat sliced bread, oat bran was replaced for baru's peel and pulp using four proportions (25,50,75, and $100 \%)$. The analysis of the chemical composition of baru's peel and pulp resulted in $21.05 \%$ moisture, $65.01 \%$ carbohydrates, $3.30 \%$ lipids, $4.45 \%$ protein, $1.79 \%$ ash, and $4.39 \%$ crude fiber. All samples were accepted considering the attributes appearance, texture, and flavor. They were considered low in total fat (2.18\%), showed no significant difference regarding the content of protein (13.59\%) and moisture (34.54\%). It presented an average content of carbohydrate of 41.90 and $1.76 \%$ of ash. There was an increase of up to $58.20 \%$ in the total content of the dietary fiber with the increase of the proportion of baru's peel and pulp. The results indicate that the peel and pulp of baru viable ingredients in the technology application to prepare whole wheat sliced bread improving nutritional characteristics and sensory attributes.
\end{abstract}

Keywords: bakery; nutrition; sensory analysis; chemical composition.

\section{Introdução}

As espécies de plantas nativas do cerrado têm-se destacado por apresentar potencial nutritivo com forte apelo sensorial e econômico, constituindo matéria-prima disponível para formulação de novos produtos alimentícios (HIANE et al., 1992).

Das espécies nativas do cerrado, o baru (Dipteryx Alata vog.) destaca-se pela amplitude de ocorrência e por convivência pacífica com o modelo de exploração praticado pelas populações rurais, em que as plantas são preservadas na abertura de pastos (CORREAAS et al., 2000). Possui diversos nomes populares, tais como: fruta-de-macaco, castanha-de-burro, cumaru, cumbaru, barujo, castanha-de-ferro, coco-feijão, cumaru-da-folha-grande, cumarurana, cumaru-verdadeiro, cumaru-roxo, cumbary, emburena-brava, meriparajé, e pau-cumaru (CORREA, 1931;
FERREIRA, 1980 apud BOTEZELLI; DAVIDE; MALAVASI, 2000).

O baru é constituído por uma casca fina e escura de coloração marrom, polpa com sabor adocicado e adstringente a qual abriga uma amêndoa dura e comestível. A castanha do baru, que representa $5 \%$ do rendimento em relação ao fruto inteiro, possui valor de mercado considerável; a polpa, no entanto, ainda é pouco utilizada na alimentação humana. Considerando que a polpa possa ser usada para outras finalidades, o percentual de rendimento aproveitável do fruto aumenta para mais de $50 \%$ (ALMEIDA et al., 1987 apud RIBEIRO et al., 2000).

Devido às suas características químicas, existe interesse tecnológico na casca e polpa do baru, composta principalmente

Recebido para publicação em 15/1/2008

Aceito para publicação em 7/7/2009 (003142)

${ }^{1}$ Faculdade de Nutrição, Universidade Federal de Goiás - UFG, Goiânia - GO, Brasil

2 Universidade Federal de Goiás - UFG, Goiânia-GO, Brasil, E-mail: rcardosu@fanut.ufg.br

${ }^{*}$ A quem a correspondência deve ser enviada 
por amido, fibra insolúvel e açúcares, e rica em vitaminas e sais minerais como o potássio, cobre, ferro, cálcio, fósforo e magnésio. A polpa do fruto imaturo contém elevados teores de taninos, que diminuem com a maturação do fruto, tornando o consumo dos frutos caídos no chão mais adequado (TOGASHI; SGARBIERI, 1994; VALILLO; TAVARES; AUED, 1990).

$\mathrm{O}$ uso de subprodutos agroindustriais para o incremento de produtos alimentícios garante o enriquecimento nutricional com baixo custo, além da importante tarefa do reaproveitamento destes subprodutos (BOWLES, 2005).

Devido ao seu amplo consumo enquanto fonte de carboidratos, o pão revela-se um alimento que pode ser enriquecido com subprodutos para fornecimento de nutrientes ou componentes especiais, caracterizando-o como um alimento funcional. Os componentes da fibra alimentar desempenham papel fisiológico muito importante na regulação do funcionamento do trato gastrintestinal, assim como no controle e/ou prevenção de algumas doenças crônicas não transmissíveis, despertando interesse crescente em pesquisas relacionadas às fibras dos alimentos. Concentrações significativas de fibras podem ser adicionadas ao pão para que este possa ser considerado um alimento fonte de fibras e apresente propriedades benéficas à saúde do consumidor (WANG; ROSELL; BARBER, 2002).

A possibilidade de conservação dos recursos naturais associada ao aproveitamento de produtos ou subprodutos provenientes do cerrado justifica a investigação de seu potencial para a formulação de produtos. Desta forma, a proposta deste trabalho foi avaliar a potencialidade da casca e polpa do baru como ingrediente no desenvolvimento de pães integrais do tipo fôrma e suas implicações nutricionais e sensoriais.

\section{Material e métodos}

\subsection{Material}

Baru

Os frutos do baru, coletados na região Centro-Oeste, na cidade de Pirenópolis - Go, colhidos no solo, maduros, selecionados de acordo com a integridade da casca e polpa, foram submetidos a um processo de higienização conforme recomendado por Silva Jr. (2005). A casca e polpa foram retiradas simultaneamente, de forma manual, com o auxílio de um ralador doméstico, em material inoxidável. Posteriormente foram submetidas ao processo de congelamento em embalagem plástica de polipropileno, em freezer convencional sob temperatura de $-18^{\circ} \mathrm{C}$.

\section{Pães}

A partir da formulação de um pão de fôrma integral padrão (Tabela 1), utilizando-se farinha de trigo, farelo de trigo, gérmen de trigo, fermento biológico, açúcar, margarina, sal e leite em pó, obtidos no comércio local, e água, desenvolveram-se quatro tipos de pães de fôrma utilizando-se a casca e polpa do baru
(PCB) em diferentes proporções, substituindo-se o farelo de trigo.

Quanto à formulação, os pães elaborados com casca e polpa do baru diferiram entre si e do padrão (PP) pela porcentagem de substituição do farelo de trigo por casca e polpa do baru (Tabela 2), os demais ingredientes foram mantidos na mesma proporção do pão padrão.

A mistura foi realizada incorporando todos os ingredientes para o preparo da massa de pão, seguindo uma ordem determinada, na qual primeiramente os ingredientes secos foram misturados, seguidos de adição de água. A massa foi trabalhada manualmente por 20 minutos para completa homogeneização dos ingredientes e redução da viscosidade.

A fermentação ocorreu em temperatura ambiente $\left(28^{\circ} \mathrm{C}\right)$ durante 180 minutos, divididos igualitariamente em duas etapas. Após a primeira etapa (90 minutos iniciais), a massa foi trabalhada para eliminar as bolhas de ar formadas durante a fermentação. Posteriormente, a massa foi modelada em fôrma retangular, fermentando por mais 90 minutos. Após o desenvolvimento, os pães foram assados em forno a gás, à temperatura de $180{ }^{\circ} \mathrm{C}$ por 40 minutos.

Tabela 1. Formulação do pão de fôrma integral padrão.

\begin{tabular}{lcc}
\hline \multicolumn{1}{c}{ Ingredientes } & Quantidade $(\mathrm{g})$ & Quantidade $\left(\mathrm{g} .100 \mathrm{~g}^{-1}\right)^{1}$ \\
\hline Farinha de trigo & 400 & 100 \\
Farelo de trigo & 44 & 11 \\
Gérmen de trigo & 16 & 4 \\
Fermento biológico & 6 & 1,5 \\
Sal & 8 & 2 \\
Açúcar & 48 & 12 \\
Leite em pó & 12 & 3 \\
Gordura (creme vegetal & 16 & 4 \\
com 80\% de lipídios) & & \\
Água & 258 & 64,5 \\
\hline${ }^{1}$ Com base na quantidade de farinha de trigo $(400 \mathrm{~g})$ &
\end{tabular}

Tabela 2. Proporção da casca e polpa do baru em substituição ao farelo de trigo ${ }^{1}$.

\begin{tabular}{ccccc}
\hline \multirow{2}{*}{ Formulação } & \multicolumn{2}{c}{ Farelo de trigo } & \multicolumn{2}{c}{ Casca e polpa de baru } \\
\cline { 2 - 5 } & $(\mathrm{g})$ & $\left(\mathrm{g} .100 \mathrm{~g}^{-1}\right)$ & $(\mathrm{g})$ & $\left(\mathrm{g} .100 \mathrm{~g}^{-1}\right)$ \\
\hline $\mathrm{PP}^{2}$ & 44 & 100 & 0 & 0 \\
$\mathrm{PCB}^{25}{ }^{2}$ & 33 & 75 & 25 & 11 \\
$\mathrm{PCB}_{50}{ }^{2}$ & 22 & 50 & 50 & 22 \\
$\mathrm{PCB}_{75}{ }^{2}$ & 11 & 25 & 75 & 33 \\
$\mathrm{PCB}_{100}{ }^{2}$ & 0 & 0 & 100 & 44 \\
\hline
\end{tabular}

${ }^{1}$ Com base na quantidade de farelo de trigo do pão padrão ( $11 \%$, que correspondem a $44 \mathrm{~g}$ ); ${ }^{2} \mathrm{PP}$ (Pão padrão, com 0\% de adição de casca e polpa de baru); $\mathrm{PCB}_{25}$ (Pão com 25\% de adição de casca e polpa de baru em substituição ao farelo de trigo); $\mathrm{PCB}_{50}$ (Pão com $50 \%$ de adição de casca e polpa de baru em substituição ao farelo de trigo); $\mathrm{PCB}_{75}$ (Pão com $75 \%$ de adição de casca e polpa de baru em substituição ao farelo de trigo); PCB (Pão com 100\% de adição de casca e polpa de baru em substituição ao farelo de trigo). 


\subsection{Métodos}

\section{Composição física e química}

A casca e polpa do baru foram analisadas quanto aos teores de umidade, proteínas, lipídios, carboidratos e cinzas. As mesmas análises foram realizadas para os pães, além da determinação de fibra alimentar total (FAT), volume específico e densidade.

Segundo método do Instituto Adolfo Lutz (2005), determinou-se umidade e o teor de fibras. Os lipídios foram determinados conforme descrito por Bligh e Dyer (1959), utilizando uma mistura de três solventes, clorofórmio, metanol e água. Para quantificar o teor de cinzas, foi utilizado o método de incineração em mufla a $550^{\circ} \mathrm{C}$, até obtenção de cinzas claras e de peso constante, conforme método de análise da Association of Official Agricultural Chemists - AOAC (1998). O teor de carboidratos foi obtido por diferença, isto é, a quantidade de água, proteínas, lipídios e cinzas subtraída de cem. Para estimar os carboidratos dos pães considerou-se ainda o teor de fibras para o cálculo da diferença (WILSON; SANTOS; VIEIRA, 1982).

Para o cálculo do valor energético total da casca e polpa do baru e dos pães, consideraram-se os fatores de conversão de Atwater, sendo $4 \mathrm{kcal} . \mathrm{g}^{-1}$ para proteínas e carboidratos e 9 kcal.g ${ }^{-1}$ para lipídios (MERRIL; WATT, 1963 apud WILSON; SANTOS; VIEIRA, 1982).

O volume dos pães foi determinado pelo deslocamento de sementes de painço e o volume específico dividindo-se o volume do pão $\left(\mathrm{cm}^{3}\right)$ pelo seu peso ( $\left.\mathrm{g}\right)$, (EL-DASH; CAMARGO; DIAS, 1982 apud KAJISHIMA; PUMAR; GERMANI, 2001). A densidade foi obtida pela relação massa/volume (FERREIRA; OLIVEIRA; PRETTO, 2001).

\section{Análises microbiológicas}

As análises microbiológicas da casca e polpa do baru e dos pães foram realizadas considerando-se os padrões estabelecidos pelo Regulamento Técnico sobre os padrões microbiológicos para alimentos - RDC n. 12 (BRASIL, 2001), sendo analisadas a presença de salmonella e a contagem de coliformes.

\section{Análise sensorial}

A verificação da aceitação sensorial quanto ao sabor, textura e aparência dos pães desenvolvidos foi realizada a partir do teste de aceitabilidade com escala hedônica de nove pontos conforme proposto por Moraes (1993), com ponto de corte para aceitação igual ou superior à nota seis (gostei ligeiramente).

O painel foi composto por 40 provadores não treinados, do sexo masculino e feminino, não fumantes, frequentadores das Faculdades de Nutrição e Enfermagem da Universidade Federal de Goiás.

\section{Análise estatística}

Para a análise dos dados obtidos, utilizou-se análise de variância (ANOVA) e o teste de Tukey $(\mathrm{p}<0,05)$, utilizando-se o software Instat versão 2.01. Utilizou-se análise de correlação (Pearson) entre o valor energético e o teor de fibras dos pães desenvolvidos, a partir do programa Excel for Windows, versão 2003.

\section{Resultados e discussão}

A composição centesimal da casca e polpa do baru encontra-se descrita na Tabela 3, tendo sido considerados os teores de umidade, lipídios, proteínas, carboidratos, cinzas e fibra bruta.

A avaliação do teor de umidade da casca e polpa do baru resultou em valores próximos dos encontrados por Botezelli, Davide e Malavasi (2000), que apontam valores entre 20,53 $\pm 0,54$ e 27,24 $\pm 0,53$ g. $100 \mathrm{~g}^{-1}$. Quanto às cinzas $\left(1,79 \mathrm{~g} .100 \mathrm{~g}^{-1}\right)$, valor igual foi encontrado por Vallilo, Tavares e Aued (1991), que apontam ainda um elevado teor de carboidratos presentes na polpa $\left(63,18\right.$ g.100 g $\left.\mathrm{g}^{-1}\right)$, uma baixa concentração de proteína ( 5 g. $100 \mathrm{~g}^{-1}$ ) e teor de lipídios correspondente a 4,13 g.100 g-1. Togashi e Sgarbieri (1994) encontraram valor equivalente ao deste estudo, sendo 5,59 g.100 $\mathrm{g}^{-1}$ a concentração de proteína presente na polpa do baru e 3,46 g. $100 \mathrm{~g}^{-1}$ o teor de lipídios. Filgueiras e Silva (1975) encontraram valor de 10,13 g.100 g para proteínas, o que evidencia que a composição centesimal pode variar em função da forma de cultivo, da região de cultivo do baru e do método de análise utilizado.

O valor energético estimado da casca e polpa do baru, considerando-se proteínas, lipídios e carboidratos, foi de $307,54 \mathrm{kcal} .100 \mathrm{~g}^{-1}$, sendo a maior contribuição para este aporte calórico proveniente do grupo dos carboidratos. A amêndoa do baru apresentou valor energético de $560 \mathrm{kcal} .100 \mathrm{~g}^{-1}$, com maior aporte relacionado ao teor de lipídios (VALLILO; TAVARES; AUED, 1991).

A composição centesimal dos pães desenvolvidos foi determinada considerando-se os teores de umidade, proteínas, lipídios, carboidratos, cinzas e FAT, conforme expressado na Tabela 4 .

Com relação aos teores de lipídios, as amostras enquadramse nos valor estabelecido pela legislação para alimentos sólidos com baixo teor de gorduras totais, com valores inferiores a 3 g.100 g-1 (BRASIL, 1998).

Tabela 3. Composição centesimal da casca e polpa de baru (g. $\left.100 \mathrm{~g}^{-1}\right)$.

\begin{tabular}{lr}
\hline Determinação & \multicolumn{1}{c}{ g.100 g $\mathrm{g}^{-1}$} \\
\hline Umidade & $21,05 \pm 0,05$ \\
Carboidratos & $65,01 \pm 0,19$ \\
Lipídios & $3,30 \pm 0,26$ \\
Proteínas & $4,45 \pm 0,06$ \\
Cinzas & $1,79 \pm 0,01$ \\
Fibra bruta & $4,39 \pm 0,16$ \\
\hline
\end{tabular}


Tabela 4. Composição centesimal do pão padrão e dos pães elaborados com a casca e polpa do baru (g.100 g $\left.\mathrm{g}^{-1}\right)$.

\begin{tabular}{|c|c|c|c|c|c|}
\hline \multirow[t]{2}{*}{ Parâmetro } & \multicolumn{5}{|c|}{ Amostras } \\
\hline & $\mathrm{PP}^{2}$ & $\mathrm{PCB}_{25}{ }^{2}$ & $\mathrm{PCB}_{50}{ }^{2}$ & $\mathrm{PCB}_{75}{ }^{2}$ & $\mathrm{PCB}_{100}{ }^{2}$ \\
\hline Umidade & $35,00 \pm 0,23^{\mathrm{a}}$ & $32,67 \pm 0,57^{\mathrm{a}}$ & $35,30 \pm 0,12^{\mathrm{a}}$ & $35,13 \pm 0,19^{a}$ & $34,62 \pm 0,43^{\mathrm{a}}$ \\
\hline Cinzas & $1,90 \pm 0,21^{\mathrm{a}}$ & $2,00 \pm 0,01^{\mathrm{b}}$ & $1,22 \pm 0,0^{c}$ & $1,80 \pm 0,03^{\mathrm{d}}$ & $1,90 \pm 0,02^{\mathrm{a}}$ \\
\hline Lipídios & $2,20 \pm 0,09^{a}$ & $2,31 \pm 0,09^{a}$ & $2,38 \pm 0,06^{a}$ & $1,95 \pm 0,15^{\mathrm{b}}$ & $2,08 \pm 0,2^{\mathrm{ab}}$ \\
\hline Proteínas & $14,13 \pm 0,75^{a}$ & $13,50 \pm 0,36^{\mathrm{a}}$ & $14,00 \pm 0,20^{\mathrm{a}}$ & $12,97 \pm 0,60^{\mathrm{a}}$ & $13,37 \pm 0,31^{\mathrm{a}}$ \\
\hline Carboidratos & $42,37 \pm 0,30^{\mathrm{a}}$ & $44,25 \pm 1,13^{\mathrm{b}}$ & $40,93 \pm 0,76^{\mathrm{ac}}$ & $41,35 \pm 0,39^{\mathrm{ac}}$ & $40,60 \pm 0,02^{c}$ \\
\hline
\end{tabular}

${ }^{1}$ Médias com letras iguais na mesma linha não diferem significativamente entre si ( $<<0,05$ ); e ${ }^{2} \mathrm{PP}$ (Pão padrão com $0 \%$ de adição de casca e polpa de baru); PCB (Pão com $25 \%$ de adição de casca e polpa de baru em substituição ao farelo de trigo); $\mathrm{PCB}_{50}$ (Pão com $50 \%$ de adição de casca e polpa de baru em substituição ao farelo de trigo); $\mathrm{PCB}_{75}$ (Pão com $75 \%$ de adição de casca e polpa de baru em substituição ao farelo de trigo); PCB $_{100}$ (Pão com $100 \%$ de adição de casca e polpa de baru em substituição ao farelo de trigo).

Quanto aos teores de fibra alimentar, que variou de 4,52 a 7,15 g.100 g $\mathrm{g}^{-1}$, observou-se um acréscimo significativo entre as diferentes formulações com o aumento da proporção da $\mathrm{PCB}$ em substituição ao farelo de trigo. Os pães $\mathrm{PP}$ e $\mathrm{PCB}_{25}$ classificam-se como alimentos fonte de fibra. A amostra com $100 \%$ de $\mathrm{PCB}\left(\mathrm{PCB}_{100}\right)$ foi a que apresentou maior aumento no conteúdo de FAT, sendo na ordem de 58,2\%, com 7,15 g.100 g-1 de fibra. Os pães elaborados com substituição do farelo acima de $50 \%$ apresentaram teores de fibra superiores a 6 g. $100 \mathrm{~g}^{-1}$, caracterizando-se como alimentos ricos em fibra (BRASIL, 1998).

Quanto ao valor energético estimado, observou-se sua redução à medida que aumentou a concentração de fibras, conforme análise de correlação $(r=-0,82)$. De acordo com Stauffer (1990) apud Benassi, Watanabe e Lobo (2001), existem duas razões para se adicionar fibra em pães, sendo a primeira o aumento do teor de fibra alimentar consumida e, a segunda, o decréscimo do conteúdo calórico destes pães.

Na Tabela 5, estão apresentados os valores nutricionais dos pães elaborados com PCB, do pão integral padrão e de um pão de fôrma integral comercial.

Quando comparados com um pão integral comercial (PC), com base na Ingestão Diária Recomendada (IDR), os pães desenvolvidos com casca e polpa de baru atendem a uma maior percentagem do valor diário de referência quanto ao teor de proteínas e fibras, e menor percentagem de lipídios e igual teor para os carboidratos, conforme apresentado na Figura 1.

O volume específico encontrado apresentou intervalo de 3,84 a $4,09 \mathrm{~cm}^{3} \cdot \mathrm{g}^{-1}$ (Tabela 6). Gandra et al. (2008) obtiveram valores de 3,77 e $4,40 \mathrm{~cm}^{3} \cdot \mathrm{g}^{-1}$ em pães de fôrma enriquecidos com fibras e adicionados de lípase e monoglicerídeos. Em pães do tipo fôrma fortificados com ferro, Nabeshima et al. (2005) relatam volume específico variando de 3,03 a $3,54 \mathrm{~cm}^{3} \cdot \mathrm{g}^{-1}$. Katina et al. (2006) apresentaram valor de $4,1 \mathrm{~cm}^{3} \cdot \mathrm{g}^{-1}$ para o volume específico de pães de fôrma com alto teor de fibras e com adição de misturas de enzimas. Bonet et al. (2006) relataram volumes específicos variando de 3,41 a $4,42 \mathrm{~cm}^{3} \cdot \mathrm{g}^{-1}$ em pães adicionados de glicose oxidase.

De acordo com Bushuk (1985) apud Gutkoski e Jacobsen Neto (2002), o volume do pão geralmente é proporcional ao conteúdo de proteína bruta. A adição de glúten, de agentes
Tabela 5. Composição nutricional em $50 \mathrm{~g}^{1}$ de pães elaborados com casca e polpa de baru, pão padrão e pão integral tipo comercial.

\begin{tabular}{lcccccc}
\hline \multicolumn{1}{c}{ Parâmetro } & $\mathrm{PC}^{2}$ & $\mathrm{PP}^{2}$ & $\mathrm{PCB}_{25}{ }^{2}$ & $\mathrm{PCB}_{50}{ }^{2}$ & $\mathrm{PCB}_{75}{ }^{2}$ & $\mathrm{PCB}_{100}{ }^{2}$ \\
\hline Valor energético (kcal) & 118 & 123 & 126 & 120 & 117 & 117 \\
Carboidratos (g) & 20 & 21 & 22 & 20 & 21 & 20 \\
Proteínas (g) & 5,2 & 7,1 & 6,7 & 7 & 6,5 & 6,7 \\
Gorduras totais (g) & 1,8 & 1,1 & 1,1 & 1,2 & 1,0 & 1,0 \\
FAT (g) & 2,7 & 2,3 & 2,7 & 3,1 & 3,3 & 3,6 \\
\hline
\end{tabular}

${ }^{1}$ Correspondente a 2 fatias de pão integral (PINHEIRO et al., 1998); $\mathrm{e}^{2} \mathrm{PC}$ (pão de fôrma integral comercial); $\mathrm{PP}$ (Pão padrão com 0\% de adição de casca e polpa de baru); $\mathrm{PCB}_{25}$ (Pão com $25 \%$ de adição de casca e polpa de baru em substituição ao farelo de trigo); $\mathrm{PCB}_{50}$ (Pão com 50\% de adição de casca e polpa de baru em substituição ao farelo de trigo); $\mathrm{PCB}_{75}$ (Pão com $75 \%$ de adição de casca e polpa de baru em substituição ao farelo de trigo); $\mathrm{PCB}_{100}$ (Pão com $100 \%$ de adição de casca e polpa de baru em substituição ao farelo de trigo).

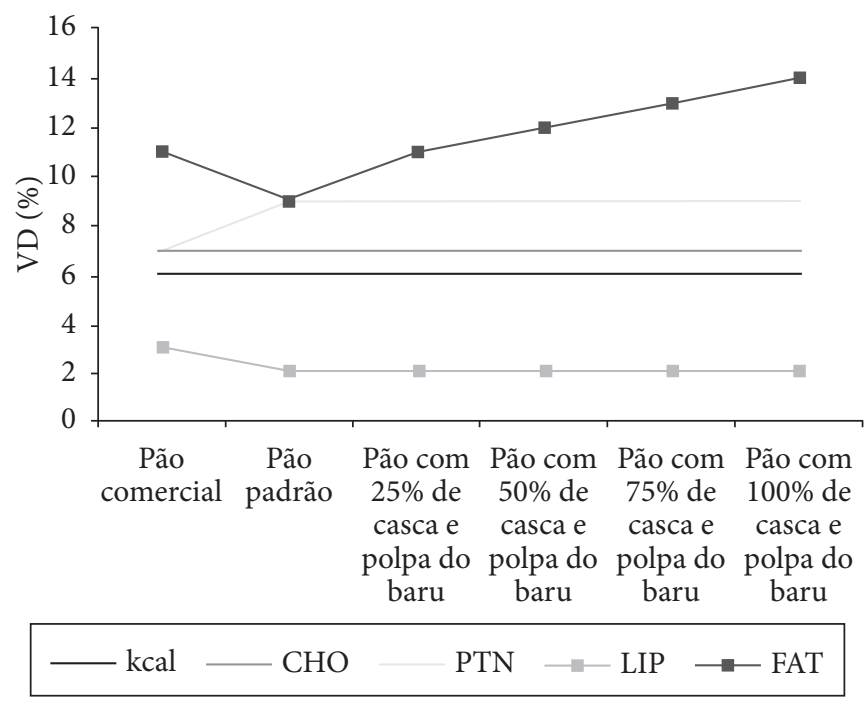

Figura 1. Comparação do valor diário de ingestão de pães elaborados com casca e polpa de baru, pão padrão e pão integral tipo comercial, com base em uma dieta de $2.000 \mathrm{kcal}$.

oxidantes, de alguns emulsificantes e de enzimas melhora a retenção dos gases e, consequentemente, o volume final (GANDRA et al., 2008).

Os resultados encontrados neste trabalho sugerem uma interação entre os componentes do farelo de trigo e da casca 
e polpa de baru, resultando em volumes específicos inferiores nos produtos com mistura destes ingredientes, o que não ocorre nas formulações com utilização de apenas um dos ingredientes (farelo de trigo ou polpa e casca de baru), os quais apresentam volumes específicos semelhantes $(\mathrm{p}<0,05)$ (Tabela 6).

A ausência de utilização de melhoradores, bem como a tecnologia simples empregada, justifica os baixos valores para volume específico encontrados neste trabalho, entretanto não houve comprometimento da textura quando avaliada sensorialmente.

A análise microbiológica da casca e polpa do baru e dos pães (Tabela 7) apresentou-se de acordo com os padrões estabelecidos pelo item 10.d da resolução - $\mathrm{RDC}{ }^{\circ} 12$, de 02 de janeiro de 2001, da Agência Nacional de Vigilância Sanitária do Ministério da Saúde, em todas as amostras (BRASIL, 2001), demonstrando qualidade sanitária em todas as etapas de produção (SILVA Jr. 2005).

A aceitabilidade dos pães foi avaliada quanto aos atributos sabor, textura e aparência. Considerando-se o ponto de corte para aceitação igual à nota seis (gostei ligeiramente), todas as amostras foram aceitas, conforme expresso na Tabela 8, com variação dos valores hedônicos de 6,0 a 7,5 (gostei ligeiramente a gostei regularmente).

Quanto ao sabor, a amostra com maior aceitação foi a $\mathrm{PCB}_{25}$, com nota 7 (Figura 2). O sabor é o atributo mais

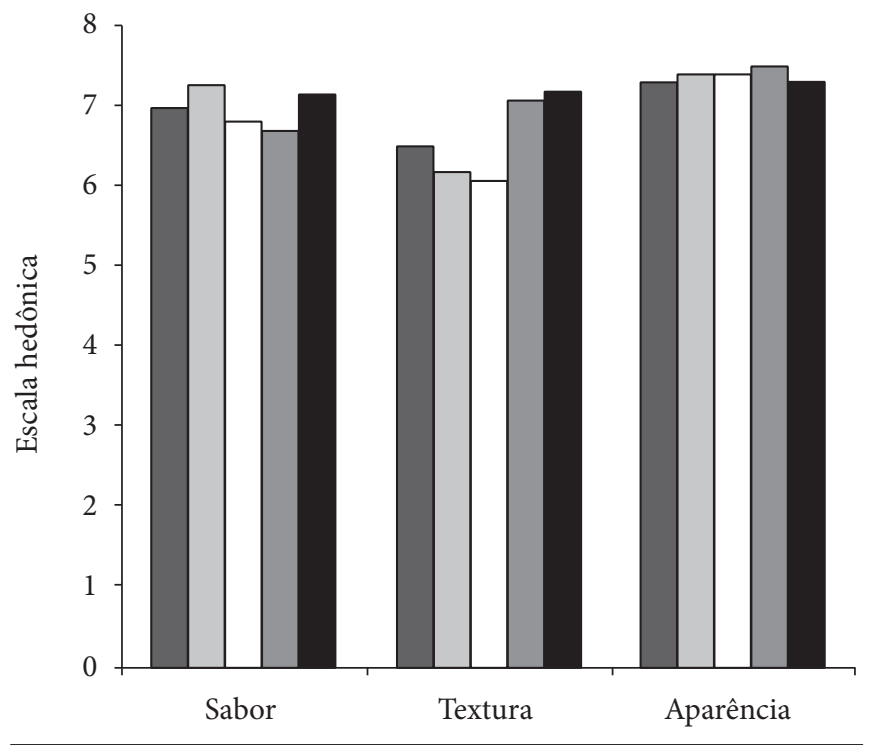

Pão padrão $\square$ Pão com $25 \%$ de casca e polpa do baru

$\square$ Pão com $50 \%$ de casca e polpa do baru

Pão com 75\% de casca e polpa do baru

Pão com $100 \%$ de casca e polpa do baru

Figura 2. Valores médios de aceitabilidade dos pães.

Tabela 6. Parâmetros físicos dos pães elaborados com PCB (polpa e casca de baru) e do PP (pão padrão).

\begin{tabular}{lccccc}
\hline \multirow{2}{*}{ Parâmetro } & \multicolumn{5}{c}{ Amostras } \\
\cline { 2 - 6 } & PP2 & PCB252 & PCB502 & PCB752 & PCB1002 \\
\hline Volume específico $\left(\mathrm{cm}^{3} \cdot \mathrm{g}^{-1}\right)$ & $4,09 \pm 0,10^{\mathrm{a}}$ & $2,22 \pm 0,17^{\mathrm{b}}$ & $2,5 \pm 0,21^{\mathrm{b}}$ & $1,76 \pm 0,13^{\mathrm{b}}$ & $3,84 \pm 0,20^{\mathrm{a}}$ \\
Densidade $\left(\mathrm{cm}^{3} \cdot \mathrm{g}^{-1}\right)$ & $0,22 \pm 0,02^{\mathrm{a}}$ & $0,45 \pm 0,02^{\mathrm{b}}$ & $0,46 \pm 0,01^{\mathrm{b}}$ & $0,57 \pm 0,05^{\mathrm{c}}$ & $0,25 \pm 0,01^{\mathrm{a}}$ \\
\hline
\end{tabular}

${ }^{1}$ Médias com letras iguais na mesma linha não diferem significativamente entre si ( $<<0,05$ ); $\mathrm{e}^{2} \mathrm{PP}$ (Pão padrão com $0 \%$ de adição de casca e polpa de baru); $\mathrm{PCB}_{25}$ (Pão com $25 \%$ de adição de casca e polpa de baru em substituição ao farelo de trigo); $\mathrm{PCB}_{50}$ (Pão com $50 \%$ de adição de casca e polpa de baru em substituição ao farelo de trigo); $\mathrm{PCB}_{75}$ (Pão com $75 \%$ de adição de casca e polpa de baru em substituição ao farelo de trigo); $\mathrm{PCB}_{100}$ (Pão com 100\% de adição de casca e polpa de baru em substituição ao farelo de trigo).

Tabela 7. Análise microbiológica do pão padrão e dos pães elaborados com casca e polpa de baru.

\begin{tabular}{|c|c|c|c|c|c|c|}
\hline \multirow[t]{2}{*}{ Análise } & \multirow[t]{2}{*}{$\mathrm{VMP}^{1}$} & \multicolumn{5}{|c|}{ Valores encontrados } \\
\hline & & $\mathrm{PP} 2$ & PCB252 & PCB502 & PCB752 & PCB1002 \\
\hline Contagem de coliformes a $45^{\circ} \mathrm{C} / \mathrm{g}$ & $1,0 \times 10^{2}$ UFC. $^{-1}$ ou mL & $<10$ UFC.g $^{-1}$ & $<10$ UFC. $^{-1}$ & $<10$ UFC. $^{-1}$ & $<10$ UFC. $^{-1}$ & $<10$ UFC. $^{-1}$ \\
\hline Presença de salmonella sp/25g & Ausência em $25 \mathrm{~g}$ & $\begin{array}{c}\text { Ausente em } \\
25 \mathrm{~g}\end{array}$ & $\begin{array}{c}\text { Ausente em } \\
25 \mathrm{~g}\end{array}$ & $\begin{array}{c}\text { Ausente em } \\
25 \mathrm{~g}\end{array}$ & $\begin{array}{c}\text { Ausente em } \\
25 \mathrm{~g}\end{array}$ & $\begin{array}{c}\text { Ausente em } \\
25 \mathrm{~g}\end{array}$ \\
\hline
\end{tabular}

${ }^{1}$ Valor Máximo Permitido conforme Brasil (2001); e ${ }^{2} \mathrm{PP}$ (Pão padrão com $0 \%$ de adição de casca e polpa de baru); $\mathrm{PCB}_{25}$ (Pão com $25 \%$ de adição de casca e polpa de baru em substituição ao farelo de trigo); $\mathrm{PCB}_{50}$ (Pão com $50 \%$ de adição de casca e polpa de baru em substituição ao farelo de trigo); $\mathrm{PCB}_{75}$ (Pão com $75 \%$ de adição de casca e polpa de baru em substituição ao farelo de trigo); $\mathrm{PCB}_{100}$ (Pão com 100\% de adição de casca e polpa de baru em substituição ao farelo de trigo).

Tabela 8. Análise sensorial do pão padrão e dos pães elaborados com PCB.

\begin{tabular}{lccccc}
\hline \multirow{2}{*}{ Parâmetro } & \multicolumn{5}{c}{ Amostras } \\
\cline { 2 - 6 } & PP2 & PCB252 & PCB502 & PCB752 & PCB1002 \\
\hline Sabor & $6,97 \pm 1,42^{\mathrm{a}}$ & $7,27 \pm 1,28^{\mathrm{a}}$ & $6,82 \pm 1,28^{\mathrm{a}}$ & $6,67 \pm 1,84^{\mathrm{a}}$ & $7,12 \pm 1,65^{\mathrm{a}}$ \\
Aparência & $7,32 \pm 1,27^{\mathrm{a}}$ & $7,45 \pm 1,20^{\mathrm{a}}$ & $7,42 \pm 1,26^{\mathrm{a}}$ & $7,50 \pm 1,17^{\mathrm{a}}$ & $7,30 \pm 1,16^{\mathrm{a}}$ \\
Textura & $6,57 \pm 2,07^{\mathrm{a}}$ & $6,17 \pm 1,88^{\mathrm{a}}$ & $6,07 \pm 1,99^{\mathrm{a}}$ & $7,05 \pm 1,91^{\mathrm{a}}$ & $7,15 \pm 1,61^{\mathrm{a}}$ \\
\hline
\end{tabular}

${ }^{1}$ Médias com letras iguais na mesma linha não diferem significativamente entre si ( $\left.<<0,05\right)$; e ${ }^{2} \mathrm{PP}$ (Pão padrão com $0 \%$ de adição de casca e polpa de baru); PCB (Pão com $25 \%$ de adição de casca e polpa de baru em substituição ao farelo de trigo); $\mathrm{PCB}_{50}$ (Pão com $50 \%$ de adição de casca e polpa de baru em substituição ao farelo de trigo); $\mathrm{PCB}_{75}$ (Pão com $75 \%$ de adição de casca e polpa de baru em substituição ao farelo de trigo); PCB $_{100}$ (Pão com $100 \%$ de adição de casca e polpa de baru em substituição ao farelo de trigo). 
apreciado em um alimento (ESTELLER; LANNES, 2005). A amostra $\mathrm{PCB}_{100}$ apresentou maior aceitação para textura (nota $=7$ ). A textura para produtos panificados é dependente da formulação: qualidade da farinha, quantidade de açúcares, gorduras, emulsificantes, enzimas e mesmo a adição de glúten e melhoradores de farinha; umidade da massa e conservação (ESTELLER; LANNES, 2005). Para o atributo aparência a amostra com maior nota de aceitação foi $\mathrm{PCB}_{75}($ nota $=7)$.

\section{Conclusões}

Pães desenvolvidos com diferentes proporções de casca e polpa de baru em substituição ao farelo de trigo apresentam aceitação quanto aos atributos de aparência, textura e sabor. Há redução do valor energético e acréscimo em até 58,2\% no teor de fibra alimentar total entre diferentes formulações com o aumento da proporção da casca e polpa do baru. Com baixo teor de gorduras totais, não houve diferença significativa entre as amostras quanto ao teor de proteína e umidade. Todas as amostras apresentaram-se de acordo com os padrões microbiológicos estabelecidos pela legislação.

A casca e polpa do baru constituem ingredientes viáveis para aplicação tecnológica na elaboração de pães integrais do tipo fôrma, conferindo melhora das características nutricionais e atributos sensoriais. Novos estudos devem ser realizados quanto à utilização da casca e polpa do baru em substituição aos ingredientes convencionais utilizados na fabricação de produtos panificados.

\section{Referências bibliográficas}

ASSOCIATION OF OFFICIAL ANALYTICAL CHEMISTS - AOAC. Official methods of analysis. 16 ed. Washington: AOAC, 1998. $1018 \mathrm{p}$.

BENASSI, V. T.; WATANABE, E.; LOBO, A. R. Produtos de panificação com conteúdo calórico reduzido. Boletim do Centro de Pesquisas e Processamento de Alimentos, v. 19, n. 2, p. 225-242, 2001.

BLIGH, E. G.; DYER, W. J. A rapid method of total lipid extraction and purification. Canadian Journal Biochemistry and Physiology, v. 37, n. 8, p. 911-917, 1959.

BONET, A. et al. Glucose oxidase effect on dough rheology and bread quality: a study from macroscopic to molecular level. Food Chemistry, v. 99, n. 2, p. 408-415, 2006.

BOTEZELLI, L.; DAVIDE, A. C; MALAVASI, M. M. Características dos frutos e sementes de quatro procedências de Dipteryx alata vogel (baru). Cerne, v. 6, n. 1, p. 9-18, 2000.

BOWLES, S. Utilização do subproduto da obtenção de extrato aquoso de soja okara em pães do tipo francês. Ponta Grossa, 2005. 87 p. Tese (Mestrado em Ciência e Tecnologia de Alimentos) - Universidade Estadual de Ponta Grossa - UEPG.

BRASIL. Ministério da Saúde. Portaria n 27, de 13 de janeiro de 1998. Aprova o regulamento técnico referente à informação nutricional complementar. Diário Oficial da União Diário Oficial da União. Poder Executivo, Brasília, DF, 16 de Janeiro de 1998. Disponível em: <http://www.anvisa.gov.br>. Acesso em: Março 2006.

BRASIL. Ministério da Saúde. Resolução RDC n. 12, de 02 de janeiro de 2001. Aprova o regulamento técnico sobre os padrões microbiológicos para alimentos. Diário Oficial da União Diário Oficial da União. Poder Executivo, Brasília, DF, 02 de Janeiro de
2001. Disponível em: <http://www.anvisa.gov.br>. Acesso em: Março 2006.

CORREA, M. P. Dicionário das plantas úteis do Brasil e das exóticas cultivadas. Rio de janeiro: Ministério da agricultura, 1931. p. 476-477. (v. 2).

CORRÊAS, G. C. et al. Caracterização física de frutos de baru (Dipteryx alata Vog.) em três populações nos cerrados do Estado de Goiás. Pesquisa Agropecuária Tropical, v. 30, n. 2, p. 5-11, 2000.

ESTELLER, M. S.; LANNES, C. S. Parâmetros complementares para fixação de identidade e qualidade de produtos panificados. Ciência e Tecnologia de Alimentos, v. 25, n. 4, p. 802-806, 2005.

FERREIRA, S. M. R.; OLIVEIRA, P. V.; PRETTO, D. Parâmetros de qualidade do pão francês. Boletim do Centro de Pesquisas e Processamento de Alimentos, v. 19, n. 2, p. 301-318, 2001.

FILGUEIRAS, T. S.; SILVA, E. Estudo preliminar do baru. Brasil Florestal, v. 6, n. 22, p. 33-39, 1975.

GANDRA, K. M. et al. Aplicação de lipase e monoglicerídeo em pão de forma enriquecido com fibras. Ciência e Tecnologia de Alimentos, v. 28, n. 1, p. 182-192, 2008.

GUTKOSKI, L. C.; JACOBSEN NETO, R. Procedimento para teste laboratorial de panificação: pão tipo forma. Ciência Rural, v. 32, n. 5, p. 873-879, 2002.

HIANE, A. P. et al. Composição centesimal e perfil de ácidos graxos de alguns frutos nativos do Estado de Mato Grosso do sul. Boletim do Centro de Pesquisas e Processamento de Alimentos, v. 10, n. 1, p. 35-42, 1992.

INSTITUTO ADOLFO LUTZ - IAL. Normas analíticas do Instituto Adolfo Lutz: métodos químicos e físicos para análise de alimentos. 4 ed. Brasília: Ministério da Saúde, 2005. 1018 p. (série A, Normas e manuais técnicos).

KAJISHIMA, S.; PUMAR, M.; GERMANI, R. Elaboração de pão francês com farinha enriquecida de sulfato de cálcio. Boletim do Centro de Pesquisas e Processamento de Alimentos, v. 19, n. 2, p. 157-168, 2001.

KATINA, K. et al. Effects of sourdough and enzymes on staling of high-fiber wheat bread. LWT - Food Science and Technology, v. 39, n. 5, p. 479-491, 2006.

MORAES, M. A. C. Métodos para avaliação sensorial dos alimentos. 8 ed. Campinas: UNICAMP, 1993. 93 p.

NABESHIMA, E. H. et al. Propriedades tecnológicas e sensoriais de pães fortificados co ferro. Ciência e Tecnologia de Alimentos, v. 25, n. 3, p. 506-511, 2005.

RIBEIRO, J. F. et al. Baru (Dipteryx alata vogel) Jaboticabal: Funep, 2000. $41 \mathrm{p}$.

SILVA Jr., E. A. Manual de controle higiênico-sanitário em alimentos. 6 ed. São Paulo: Varela, 2005. 623 p.

TOGASHI, M.; SGARBIERI, V. C. Caracterização química parcial do fruto do baru (Dipteryx alata vogel). Ciência e Tecnologia de Alimentos, v. 14, n. 1, p. 85-95, 1994.

VALILLO, M. I.; TAVARES, M.; AUED, S. Composição química da polpa e da semente do fruto do cumbaru (Dipteryx alata vogel): caracterização do óleo da semente. Revista do Instituto Florestal, v. 2, n. 2, p. 115-125, 1990.

WANG, G. J.; ROSELL, C. M.; BARBER, C. B. Effects of the addition of different fibres on wheat dough performance and bread quality. Food Chemistry, v. 79, n. 2, p. 221-226, 2002.

WILSON, E. D.; SANTOS, A. C.; VIEIRA, E. C. Energia. In: OLIVEIRA, J. E. D.; SANTOS, A. C.; WILSON, E. D. (Coords.). Nutrição básica. São Paulo: Sarvier, 1982. p. 79-97. 